\title{
O papel do conselheiro municipal de saúde na fiscalização do orçamento público
}

The role of the municipal health counsellor in the supervision of public budget

Elisama Nascimento Rocha', Juliana Xavier Pinheiro da Cunha², Laís Santana Santos Pereira Lira³, Lucinéia Braga de Oliveira ${ }^{4}$, Adriana Alves Nery ${ }^{5}$ Alba Benemérita Alves Vilela ${ }^{6}$, Fabio Ornellas Prado ${ }^{7}$

'Mestranda em Enfermagem e Saúde pela Universidade Estadual do Sudoeste da Bahia (UESB) - Vitória da Conquista (BA). Enfermeira Pesquisadora da Universidade Estadual do Sudoeste da Bahia (UESB) - Vitória da

Conquista (BA), Brasil.

elisamapq@hotmail.com

${ }^{2}$ Mestranda em Enfermagem e Saúde do Programa de Pós-Graduação em Enfermagem e Saúde pela Universidade Estadual do Sudoeste da Bahia (UESB) - Vitória da Conquista (BA). Bolsista da Coordenação de Aperfeicoamento de Pessoal de Nível Superior (CAPES) - Brasília (DF), Brasil. julianaxcunha@gmail.com

${ }^{3}$ Mestre em Enfermagem e Saúde pelo Programa de Pós-Graduação em Enfermagem e Saúde com ênfase em Saúde Pública, da Universidade Estadual do Sudoeste da Bahia (UESB) - Vitória da Conquista (BA). Pesquisadora do Programa de Educação pelo Trabalho (PET) em Saúde Mental: Crack, Álcool e Outras Drogas, na Secretaria Municipal de Jequié (BA), Brasil. lailira@hotmail.com

${ }^{4}$ Mestranda do Programa de Pós-Graduação em Enfermagem e Saúde pela Universidade Estadual do Sudoeste da Bahia (UESB) - Jequié (BA). Professora da Secretaria Municipal de Educação de Jequié (BA). Professora colaboradora do Centro de PósGraduação, Pesquisa e Extensão (CEPPEX) da Universidade Estadual do Sudoeste da Bahia (UESB) - Jequié (BA), Brasil. neia.braga@hotmail.com

5 Doutora em Enfermagem em Saúde Pública pela Escola de Enfermagem de Ribeirão Preto, da Universidade de São Paulo (USP)

- Ribeirão Preto (SP). Professora titular da

Universidade Estadual do Sudoeste da Bahia

(UESB) - Jequié (BA), Brasil.

aanery@gmail.com

Doutora em Enfermagem pela Universidade Federal do Ceará (UFC) - Fortaleza (CE). Professora da Universidade Estadual do

Sudoeste da Bahia (UESB) - Jequié (BA), Brasil. albavilela@gmail.com

Doutor em Estomatopatologia pela Universidade Estadual de Campinas (UNICAMP) - Campinas (SP). Professo Adjunto Doutor da Universidade Estadual do Sudoeste da Bahia (UESB) - Jequié (BA), Brasil. fop_@hotmail.com
RESUMO Este estudo tem por objetivo analisar o conhecimento de conselheiros municipais de saúde sobre os seus papéis na fiscalização do orçamento público. É um estudo descritivo-exploratório, realizado com seis conselheiros do município de Jequié-BA. Os dados foram coletados através de questionário e entrevista semiestruturada, e analisados pela técnica de análise de conteúdo de Bardin (2009). Da análise, emergiram quatro categorias temáticas, através das quais se verificou que os conselheiros demonstraram consciência dos seus papéis de fiscalizar e acompanhar os recursos financeiros do Sistema Único de Saúde (SUS) e de favorecer a efetivação do controle social na fiscalização do orçamento público.

PALAVRAS CHAVE: Conselhos de Saúde; Participação Comunitária; Financiamento em Saúde.

\begin{abstract}
This study aims to analyze the knowledge of Municipal Health Counselors about their role in overseeing the public budget. It is a descriptive exploratory study, conducted with six counselors in the city of Jequié-BA. Data were collected through questionnaires and semistructured interviews and analyzed using content analysis technique of Bardin (2009). From the analysis four thematic categories emerged where it was found that the counselor demonstrated awareness of their role to oversee and monitor the financial resources of the SUS (Sistema Único de Saúde) - Unified Health System - and to foster effective social control in the supervision of the public budget.
\end{abstract}

KEYWORDS: Health Councils; Community Participation; Funding in Health. 


\section{Introdução}

A criação do Sistema Único de Saúde (SUS), na década de 1980, foi fruto de muitas lutas e conquistas vivenciadas nas arenas política e social no Brasil. A partir desse período, vários avanços nas políticas de saúde puderam ser sentidos pela sociedade. Dentre eles, a participação popular com a inclusão de novos atores sociais no processo decisório repercutiu de maneira positiva para o fortalecimento da democracia.

O exercício da participação popular acontece em várias instâncias da sociedade, principalmente, através dos Conselhos de Saúde, que concentram um número significativo de cidadãos que têm como função fiscalizar e deliberar sobre o funcionamento do SUS em todo o País. Essa participação popular no SUS ocorre através do controle social, que tem por objetivo a democratização do Estado através da participação da sociedade nas políticas públicas (OLIVEIRA, 2004).

Para se concretizar a democracia pelo controle social é fundamental, no processo decisório das políticas públicas, a participaçấo de diversos setores da sociedade através de sua representação nos Conselhos de Saúde. Esses representantes terão os desafios de conciliar a competição e a articulação política, e de romper com o ciclo de subordinação e injustiças sociais a fim de fortalecer a cidadania (MOREIRA, 2009).

Como diretriz do SUS, a participação social é regulamentada pela Lei $\mathrm{n}^{\circ}$ 8.142, tendo como uma das instâncias colegiadas o Conselho de Saúde. Este, composto por representantes do governo, prestadores de serviço, profissionais de saúde e usuários, é responsável pela formulação de estratégias e pelo controle da execução da política de saúde, inclusive, no que se refere aos aspectos econômicos e financeiros (BRASIL, 1990b).

Dentre as discussóes sobre os desafios para a implementação do SUS, o financiamento tem se tornado uma preocupação permanente, tanto dos gestores quanto dos diversos setores da sociedade. Garantir o atendimento universal e integral em meio a um cenário de restriçôes orçamentárias e financeiras, e alocar recursos de maneira equânime diante das desigualdades sociais e regionais de um país como o Brasil, torna-se um grande desafio (BRASIL, 2007).
Os gastos realizados a partir das necessidades da área de saúde pública estão submetidos às diretrizes e aos princípios do SUS, destinados às ações e aos serviços de acesso universal, gratuito e igualitário. A Lei Orgânica da Saúde (Lei no 8080/90) define que o depósito dos recursos financeiros do SUS deve ser realizado em conta especial, em cada esfera de atuação, e a fiscalização da sua movimentação é de responsabilidade dos Conselhos de Saúde. Já a Lei no 8.142 define que os Municípios, Estados e o Distrito Federal devem contar com o Fundo de Saúde para receberem esses recursos (BRASIL, 2003a; 1990a, 1990b).

Cada esfera de governo tem autonomia para administrar os recursos de acordo com seus Planos de Saúde aprovados pelos Conselhos de Saúde e elaborados de acordo com o Plano Nacional de Saúde. Sendo assim, os conselhos, além de estimularem a participação comunitária no controle da administração do SUS, surgem como colegiados responsáveis, também, por habilitar o recebimento dos recursos federais repassados fundo a fundo, de acordo a Lei no 8.080/90, reforçado pela Emenda Constitucional no 29/2000 (BRASIL, 2003a).

Nesse sentido, os conselheiros de saúde, na busca de efetivarem o controle social na fiscalização do orçamento público, precisam estar conscientes da responsabilidade dos seus papéis nos cenários político e social, buscando atuar de maneira eficiente a fim de obterem resultados que prezem pelos interesses sociais e pela justiça. Desta forma, este estudo tem como objetivo analisar o conhecimento de conselheiros municipais de saúde sobre os seus papéis na fiscalização do orçamento público.

\section{Método}

Trata-se de um estudo descritivo-exploratório, com abordagem qualitativa. Teve como cenário o Conselho Municipal de Saúde (CMS) do Município de JequiéBA e, como sujeitos, seis conselheiros municipais de saúde, escolhidos de forma aleatória não probabilística por conveniência.

A coleta de dados ocorreu em julho de 2011, por meio de um questionário semiestruturado composto 
por questóes sociodemográficas e entrevista semiestruturada, contendo questôes referentes ao papel do conselheiro na fiscalização do orçamento público. Os dados foram coletados após ações educativas realizadas junto aos conselheiros, que focaram temas como: processo saúde-doença; história da saúde pública no Brasil; modelos assistenciais; legislação do SUS; participação social; orçamento público; financiamento do SUS; prestação de contas; intersetorialidade e promoção da saúde; e instrumentos básicos de gestão.

As informações do questionário possibilitaram a caracterização dos sujeitos da pesquisa. Os dados obtidos por meio da entrevista foram gravados e posteriormente transcritos para análise a fim de garantir a fidelidade das informações. Após as transcrições, as entrevistas foram minuciosamente analisadas e a consolidação dos dados do presente estudo ocorreu em seguida. Para a análise dos dados de forma qualitativa foi utilizada a classificação por categorias, de acordo com a técnica de análise de conteúdo de Bardin (2009).

Atendendo à Resolução no 196/1996 do Ministério da Saúde (BRASIL, 1996), a coleta dos dados se deu após aprovação desta pesquisa, ainda em forma de projeto, pelo Comitê de Ética em Pesquisa da Universidade Estadual do Sudoeste da Bahia (UESB), sob protocolo $n^{\circ}$ 106/2011 e após leitura e assinatura do Termo de Consentimento Livre e Esclarecido pelos participantes.

\section{Resultados e Discussão}

Dos conselheiros entrevistados, $100 \%(n=6)$ eram do sexo masculino e com idades variando entre 22 e 59 anos, com média de 40,3 anos. Quanto à escolaridade, todos os entrevistados possuíam mais de nove anos de estudo, estando entre ensino médio incompleto, $16,67 \%(\mathrm{n}=1)$; ensino médio completo, 33,34\% $(\mathrm{n}=2)$; ensino superior incompleto, 33,34 \% $(\mathrm{n}=2)$; e ensino superior completo, $16,67 \%(\mathrm{n}=1)$. Com relação à profissão exercida pelos entrevistados, o resultado foi: bancário $(\mathrm{n}=1)$, estudante $(\mathrm{n}=1)$, autônomo $(\mathrm{n}=1)$, ambientalista $(\mathrm{n}=1)$, agente comunitário de saúde $(n=1)$ e agente administrativo $(n=1)$.
A média do tempo de participação dos entrevistados como conselheiro de saúde no Município foi de 1,17 anos, sendo que $83,33 \%(\mathrm{n}=5)$ deles participam há um ano e 16,67 \% (n=1) há dois anos. Todos representam, em suas atuaçóes no conselho, os usuários dos serviços de saúde.

$\mathrm{Da}$ análise das falas dos entrevistados emergiram quatro categorias relacionadas a o que atribuíam como sendo o papel do conselheiro municipal de saúde no que tange a fiscalização do orçamento público municipal. São elas: importante atribuição para a garantia do controle social; acompanhamento da gestão financeira dos recursos da saúde; avaliação da gestão orçamentária; e auxílio a outros setores na fiscalização das ações do governo.

\section{Importante atribuição para a garantia do controle social}

Essa categoria emergiu da análise das falas dos conselheiros com relação aos seus papéis na fiscalização do orçamento público, conforme se vê no depoimento abaixo:

Este é um papel importante. Nós não imaginávamos que um dia a comunidade, é... o cidadão comum teria uma responsabilidade tão grande como essa que foi atribuida através da Lei 8142 [...] eu acho também bonito quando a pessoa assume esse compromisso de fato e exerce a sua missáo de conselheiro do controle social. (E1).

O nosso papel é importantissimo porque a gente tem representaçóes do usuário como do poder público, e sabemos que através das nossas ações é que as coisas são destinadas da maneira correta. (E6).

Evidencia-se, nos depoimentos, a importância do papel do conselheiro de saúde no exercício de suas atribuiçôes. Os entrevistados enfatizam as suas responsabilidades na busca de uma gestão transparente por meio 
da participação popular a fim de garantir o controle social.

Segundo Oliveira (2004), o papel dos membros do conselho é efetivar um dos princípios norteadores do SUS, o controle social. E, para isso, vários dispositivos legais foram fundamentais para a efetivação dos Conselhos de Saúde, a começar pela Constituição Federal de 1988, que estabelece o "caráter democrático e descentralizado da gestão administrativa, com a participação da comunidade", e as leis $n^{\circ} 8080 / 90$ e $n^{\circ} 8142 / 90$, dentre outros (BRASIL, 1988; BRASIL, 1990a;1990b).

A Lei no 8142/90 ampliou a esfera de participação popular na gestão do SUS, ao possibilitar a criação dos Conselhos de Saúde, conduzindo, assim, a sociedade a uma cogestão. Esse dispositivo legal, segundo Ferreira (2006), introduziu novos atores no processo de decisão e fiscalização, na medida em que acrescentou mais responsabilização e responsividade ao processo de gestão.

Os conselhos se configuram em um importante instrumento para romper com as tradicionais formas de gestão, fazendo com que as decisões ocorram de forma democrática e transparente, através de processos participativos. Eles são os principais órgãos de controle social na definição do sistema e dos serviços de saúde, atuando na formulação de estratégias e na fiscalização operacional das políticas públicas, incluindo o controle econômico e financeiro (COTTA; CAZAL; MARTINS, 2010; OLIVEIRA, 2004).

Para isso, é fundamental que os conselheiros tenham consciência da importância e da responsabilidade dos seus papéis perante a sociedade e busquem aperfeiçoar as suas atuações pautadas na ética e na cidadania. É necessário que os mesmos saibam como agir de forma direcionada, com açóes eficazes e eficientes, conhecendo os limites para o exercício de suas funçôes a fim de não exercerem açôes arbitrárias e sem respaldo ético e legal.

Essa perspectiva corrobora a opiniáo de Saliba et al (2009), quando diz que os conselheiros de saúde precisam estar conscientes de suas missões de participação, acompanhamento e vigilância das despesas públicas, para que possam controlar quaisquer distorções e denunciá-las aos órgãos competentes.

Para que ocorra um verdadeiro controle social, Cotta, Cazal e Martins (2010) relatam que, na atuação dos gestores, é necessário que haja um deslocamento do poder de regióes verticais para regiôes horizontais. Isso possibilita uma atuação responsável, que garante a defesa dos interesses da sociedade por meio de intervenções justas e éticas.

Dessa maneira, a participação da sociedade não pode ser menosprezada, principalmente, em uma realidade como a brasileira, cuja população, em muitas situaçóes, é tratada com descaso. No Brasil, os recursos destinados à saúde são escassos e, muitas vezes, mal administrados por gestores que tratam o dinheiro público como se fosse privado (CORREIA, 2006).

Nesse sentido, os conselheiros possuem o papel essencial de fazer prevalecer a democracia e a justiça. Os Conselhos de Saúde, segundo Correia (2006), se apropriam de uma parcela do poder de governo e devem saber usá-la a favor da proposta de reforma democrática do sistema e da ampliação de seu espaço político.

Para Bravo (2000), o conselho se configura como um espaço que favorece a criação de novas bases de relação entre Estado e sociedade, possibilitando a participação de novos sujeitos políticos na construção de um espaço público democrático e, muitas vezes, de tensão entre interesses contraditórios.

Assim, é preciso que os conselheiros tenham convicção das suas responsabilidades no cenário social e político para que possam saber dirimir conflitos, e realizar controle e fiscalização, atendendo às necessidades precípuas da sociedade a fim de colaborarem para o fortalecimento do SUS.

\section{Acompanhamento da gestão financeira dos recursos da saúde}

O acompanhamento da gestão financeira se revelou como uma das principais atividades que deve ser exercida pelos conselheiros na fiscalização do orçamento público. Evidencia-se que os entrevistados têm 
conhecimento desse exercício, como pode ser observado nas seguintes falas:

No meu caso, eu vejo que... é importante, né?, o acompanhamento, of financiamento né? Porque o volume de dinheiro é alto e, às vezes, esse dinheiro não é aplicado, né?, corretamente (E2).

Então, uma das formas que o conselheiro tem pra acompanhar esses investimentos é através dos relatórios de gestão e também da prestação de contas que é feita ao conselho municipal de saúde (E3).

O papel do conselheiro na fiscalização é o acompanhamento, e ele tem que estar exigindo do gestor que seja 'mandado' para o conselho as açôes que o gestor usa, do dinheiro público (E5).

O conselheiro, ele 'estar' aqui pra fazer com que estas verbas sejam encaminhadas para os setores que realmente precisam, então, através do conselho. O conselho serve de sustentação pra que as verbas sejam destinadas para o destino correto (E6).

O acompanhamento enunciado está respaldado pela Lei no 8142/90 e pela Resoluçáo do Conselho Nacional de Saúde (CNS) no 333/2003, que preconizam que o CMS deve acompanhar e fiscalizar regularmente o desempenho das atividades financeiras e o orçamento da saúde (BRASIL, 1990b; BRASIL, 2003b).

É importante ressaltar que a resolução supracitada dispóe também sobre as competências dos conselhos e afirma que cabe a eles definir diretrizes para a elaboraçáo dos Planos de Saúde, e sobre estes deliberar. Isso deve ocorrer conforme as situaçóes epidemiológicas específicas e a capacidade organizacional dos serviços de cada município e região. Traz ainda, dentre outras atribuiçóes, que o CMS deve analisar, discutir e aprovar o relatório de gestão, com a prestação de contas e informaçôes financeiras (BRASIL, 2003b).

Algumas dessas atribuiçóes do conselheiro estiveram presentes na fala do Entrevistado 3, que enfatizou a sua participação na fiscalização do orçamento público por meio do acompanhamento do relatório de gestáo e da prestação de contas feita ao CMS.

Os CMS têm a responsabilidade de acompanhar e fiscalizar a movimentação dos recursos depositados nos fundos. É relevante destacar que, apesar dos entes federados administrarem com independência os recursos financeiros que recebem da União para a saúde, estes devem estar de acordo com o estabelecido em seus Planos de Saúde (BRASIL, 2010).

Em cada reunião do CMS, a participação se processa através das votaçóes de encaminhamentos, de resoluções e de projetos apresentados pelo Poder Executivo e outras instituiçóes de saúde, que, para receberem recursos do SUS, dependem de parecer favorável do conselho (OLIVEIRA; PINHEIRO, 2010).

Verificou-se que os entrevistados manifestaram suas preocupações com relação à administração dos recursos da saúde por parte dos gestores. Eles ressaltaram que o acompanhamento do orçamento contribui para a diminuição do desvio dos recursos públicos e para a melhoria dos serviços de saúde prestados à população.

Na prática, o controle social do SUS tem função de acompanhar e fiscalizar as despesas públicas relacionadas à saúde no Brasil. No entanto, para que os conselhos possam cumprir adequadamente as suas funções, é necessário que conheçam como funciona o orçamento da saúde, para que se efetivem como órgãos de controle e de transparência nas decisóes e açôes do poder público.

\section{Avaliação da gestão orçamentária}

Os relatos dos entrevistados retratam que a avaliação também faz parte do processo de fiscalização do orçamento público em saúde.

O Conselho de Saúde toma pra si essa responsabilidade de analisar as contas do fundo municipal de saude e dar um parecer. (E1).

O papel do conselheiro na fiscalização do orçamento público é avaliar se realmente o que foi, de alguma forma, pactuado, que foi 
direcionado para ser gasto com a saúde, realmente foi investido, e saber, também, de que forma tem sido investido. (E3).

E esse orçamento, ele vai ser avaliado pelo conselho, e, assim, o conselho pode aprovar, reprovar e solicitar modificaçôes com relação a esse orçamento, pra estar avaliando ele. (E4).

Enfatizando o que foi revelado pelos conselheiros, é imprescindível que os conselhos mantenham funcionando comissões de orçamento e/ou finanças com a missão de avaliar permanentemente a evolução dos orçamentos públicos relativos à saúde. Este controle implica na verificação de relatórios e de documentos relativos aos gastos das contas públicas.

Segundo a Resolução do CNS no 333/2003, compete aos Conselhos de Saúde analisar, discutir e aprovar o relatório de gestão, com a prestação de contas e informaçóes financeiras. Cabe também ao CMS fiscalizar, controlar gastos e deliberar sobre critérios de movimentação do Fundo de Saúde (BRASIL, 2003b).

O relatório deve ser encaminhado ao Conselho de Saúde com antecedência, para que ele tenha tempo suficiente para avaliar as informaçóes ali existentes, podendo contar com a ajuda de pessoas capacitadas. A cada dúvida sobre a aplicação dos recursos públicos, os conselheiros de saúde têm a obrigação de solicitar esclarecimentos ao gestor. Não sendo sanada a dúvida ou havendo indícios de irregularidades, deve ser apresentada denúncia aos órgãos competentes (BRASIL, 2010).

Os conselheiros devem avaliar as ações da Secretaria de Saúde em relação aos recursos financeiros, e como estes estáo sendo aplicados, no que se refere aos gastos e à movimentação do dinheiro transferido dos estados, do Distrito Federal e da União, bem como as verbas aplicadas pelo próprio município (BRASIL, 2010).

Alguns dos pesquisados demonstraram consciência de seu papel como avaliadores de documentos referentes à fiscalização do orçamento público, porém, para que esta atividade seja realizada de fato, existem outros fatores que interferem no seu andamento, como a colaboração dos gestores envolvidos no processo.

\section{Auxílio a outros setores na fiscalização das ações do governo}

Essa categoria surgiu de análise baseada no relato do papel que o conselho tem, de auxiliar outros setores na execução do controle e na fiscalização das açóes do governo, como foi verificado na fala de um dos entrevistados:

O governo procurou fazer isso criando esses conselhos, para que pudessem auxiliar também outras instituiçóes, a exemplo do Ministério Público Federal, Estadual, da Controladoria Geral da União e do próprio Ministério da Saúde, no sentido de você verificar onde, como está sendo 'feita' as contrataçóes, como estão sendo feitos os pagamentos, para evitar fraude, pra evitar o desvio de recursos. (E1).

Compete ao CMS, juntamente com o sistema de auditoria do SUS e os Tribunais de Contas, auxiliar o Poder Legislativo na fiscalização da gestão em saúde, com relação à execuçáo do plano de saúde anual, à verificação do alcance das metas estabelecidas conforme a lei de diretrizes orçamentárias, à fiscalização dos recursos, assim como à sua transferência e aplicação no SUS (BRASIL, 2004).

Segundo Oliveira (2004), cabe também ao conselho auxiliar no âmbito das três esferas de gestão do SUS (federal, estadual e municipal), na formulação de estratégias para saúde e no controle das políticas públicas e do orçamento público. Desta maneira, os conselheiros, nas suas atuaçóes, favorecem a consolidação dos princípios do SUS, na medida em que lutam pela sua efetivação por meio de açóes democráticas e participativas.

Verificou-se, através da fala do entrevistado, o conhecimento a respeito do papel do conselho frente à atuaçấo conjunta com outros setores da sociedade, no intuito de auxiliar na fiscalização e no controle do orçamento público. Esse trabalho complementar e solidário possibilita obtenção de resultados de forma mais célere, na medida em que diversos setores se mobilizam com um mesmo objetivo. 
Sendo assim, o conselho possui um importante papel no auxílio a outros órgãos, na fiscalização e no controle do orçamento público, e, para isso, é importante que o conselho se articule social e politicamente de maneira ampla a fim de contribuir para o controle social.

\section{Considerações Finais}

$\mathrm{Na}$ fiscalização do orçamento público, os CMS possuem uma importante missão através dos seus conselheiros, de fazerem prevalecer a justiça e a probidade das contas públicas da saúde. Desta forma, possibilitam que os recursos sejam administrados a favor dos interesses da sociedade, auxiliando na efetivação dos princípios norteadores do SUS, de universalidade, equidade e integralidade nos serviços e ações de saúde.

A colaboração do CMS no auxílio a outras instâncias federais, estaduais e municipais, no que tange a fiscalização do dinheiro público, foi citada por um dos participantes da pesquisa, estando, desta forma, de acordo com o que traz a legislação brasileira. Verificouse, também, que os conselheiros, sujeitos desta pesquisa, fizeram menção dos seus papéis no acompanhamento e na avaliação do orçamento para um adequado destino dos recursos à saúde. Além disso, demonstraram consciência da importância das suas funçôes sociais e políticas na consolidação do controle social.

Essa consciência de fiscalizar o orçamento público na saúde, primando pela participação popular, ajuda para que prevaleçam práticas que tenham como essência a democratização. No entanto, quando a fiscalização das contas pelo conselho ocorre de maneira a defender interesses que não condizem com os da sociedade, este conselho contribuiu para o predomínio da desigualdade e da submissão.

Nesse sentido, o conselheiro deve ter o papel de possibilitar que as informaçóes e o poder de decisão sejam partilhados com a sociedade, fazendo com que o usuário seja corresponsável, através de uma gestáo participativa. Desta maneira, o CMS fortalecerá o controle social e possibilitará que os recursos destinados à saúde sejam gastos de forma ética e responsável.

\section{Referências}

BARDIN, L. Análise de Conteúdo. 4. ed. Lisboa: Edições 70, 2009.

BRASIL. Conselho Nacional de Secretários de Saúde. O Financiamento da Saúde / Conselho Nacional de Secretários de Saúde. Brasília: CONASS, 2007. 164 p. (Coleção Progestores - Para entender a gestão do SUS, 3). Disponível em: <http://bvsms. saude.gov.br/bvs/publicacoes/colec_progestores_livro3.pdf>. Acesso em: 31 ago. 2012.

Constituição da República Federativa do Brasil. Brasília: Diário Oficial da República Federativa do Brasil, 1988.

Lei no 8.080, de 19 de agosto de 1990. Dispõe sobre as condições para a promoção, proteção e recuperação da saúde, a organização e o funcionamento dos serviços correspondentes e dá outras providências. Brasília: Diário Oficial da República Federativa do Brasil, 1990a.

Lei no 8.142, de 28 de dezembro de 1990. Dispõe sobre a participação da comunidade na gestão do Sistema Único de
Saúde (SUS) e sobre as transferências intergovernamentais de recursos financeiros na área da saúde e dá outras providências. Brasília: Diário Oficial da República Federativa do Brasil, 1990b.

Lei no 9.394, de 20 de dezembro de 1996. Estabelece as diretrizes e bases da educação nacional. Brasília: Diário Oficial da União, 1996.

Ministério da Saúde. Fundo Nacional de Saúde. Gestão Financeira do Sistema Único de Saúde: manual básico. 3. ed. rev. e ampl. Brasília: Ministério da Saúde, 2003a. 66 p. (Série A. Normas e Manuais Técnicos). Disponível em: <http://siops-homologa. datasus.gov.br/Documentacao/Manual\%20FNS.pdf>. Acesso em: 31 ago. 2012

Resolução no 333, de 4 de novembro de 2003. Aprova as diretrizes para criação, reformulação, estruturação e funcionamento dos conselhos de saúde. Brasília: Diário Oficial da União, 2003b. 
Substitutivo aos projetos de Lei Complementar no 1/2003, no 159/2004 e no 181/2004. Comissão de Seguridade Social e da Família. Regulamenta o § $3^{\circ}$ do artigo 198 da Constituição Federal e da outras providências. Brasília: Diário Oficial da União,2004; ago 11.

Tribunal de Contas da União. Orientações para conselheiros de saúde. Brasília: 4. Secretaria de Controle Externo, 2010.

BRAVO, M. I. S. Gestão Democrática na Saúde: a experiência dos Conselhos na Região Metropolitana do Rio de Janeiro. In: Encontro Nacional de Pesquisadores em Serviço Social, 7. Anais. Brasília: ABEPSS, 2000. v. III.

CORREIA, M. V. C. Controle Social na Saúde. In: MOTA, A. E. et al. (orgs.). Serviço social e saúde: formação e trabalho profissional. São Paulo: Cortez, 2006. p. 111-138. v. 1.

COTTA, R. M. M.; CAZAL, M. M.; MARTINS, P. C. Conselho Municipal de Saúde: (re) pensando a lacuna entre o formato institucional e o espaço de participação social. Ciência e Saúde Coletiva, Rio de Janeiro, v. 15, n. 5, p. 2437-2445, 2010.

FERREIRA, D. E. S. Experiências Recentes de Controle Social Sobre o Processo de Orçamentação Pública Municipal no Brasil. 2006. 80f. Trabalho de conclusão de curso (Graduação) - Escola de Administração Fazendária, Brasília, 2006. Disponível em <http://www.tesouro.fazenda.gov.br/premio_TN/XIPremio/ sistemas/2tosiXIPTN/2premio_tosi.pdf>. Acesso em: 31 ago. 2012.

MOREIRA, M. R. Democratização da Política de Saúde: avanços, limites e possibilidades dos Conselhos Municipais de Saúde. 2009. 155f. Tese (Doutorado em Saúde) - Escola Nacional de Saúde Pública, Fundação Oswaldo Cruz, Rio de Janeiro, 2009. Disponível em: <http://www.arca.fiocruz.br/bitstream/icict/2553/1/ENSP_ Tese_Moreira_Marcelo_Rasga.pdf>. Acesso em: 31 ago. 2012.

OLIVEIRA, V. C. Comunicação, informação e participação popular nos Conselhos de Saúde. Saúde e Sociedade, São Paulo, v. 13, n. 2, 2004, p. 56-69.

OLIVEIRA, L. C.; PINHEIRO, R. A participação nos conselhos de saúde e sua interface com a cultura política. Ciência \& Saúde Coletiva, Rio de Janeiro, v. 15, n. 5, p. 2455-2464, 2010.

SALIBA, N. A. et al. Conselhos de saúde: conhecimento sobre as ações de saúde. Revista de Administração Pública, Rio de Janeiro, v. 43, n. 6, p. 1369-1378, 2009.

Recebido para publicação em Setembro/2012

Versão final em Fevereiro/2013

Conflito de interesse: Não houve.

suporte financeiro: Inexistente. 